\title{
Status of common disease profile and death records among admitted child patients in medical college hospital
}

\author{
Md. Shahariar Khan ${ }^{1}$ *, Md. Rahimullah Miah ${ }^{2}$, Tania Hussain ${ }^{1}$, Syed Moosa M. A. Quaium ${ }^{1}$, Azizur Rahman ${ }^{1}$ \\ ${ }^{1}$ Department of Paediatrics, Northeast Medical College \& Hospital, Sylhet, Bangladesh \\ ${ }^{2}$ Department of Information Technology in Health, Northeast Medical College \& Hospital, Sylhet, Bangladesh \\ *Corresponding author E-mail: drmdshahariarkhan@gmail.com
}

\begin{abstract}
Background: The study assesses the common disease profile and death records among admitted child patients at the department of Paediatrics in Northeast Medical College Hospital (NEMCH) of Bangladesh.

Methodology: This was an observational study conducted in the department of Paediatrics in Medical College Hospital over a period of three years. The patients of common diseases were hundred in number surveyed through primary questionnaire in respect to their profile, diagnosis and death records. The selected common diseases were ARI, diarrhoea, protein energy malnutrition and febrile convulsion.

Results: The numbers of total admitted child patients with common diseases were 10737 for three years with the ratio of 1: 0.93 between the male and female. Out of them neonatal and general patients were 3622 and 7115 respectively. In 2018 child patients were less in numbers other than two years. ARI is more common in the end of year but diarrhoea in same added the beginning of following year. The study also represents the febrile convulsion and malnutrition are more in middle and round the year successively.

From 2017 to 2019 the death records of neonate and general at the department of NEMCH are 101 and 84 respectively. Indeed, it is a good sign to reducing the unwanted death in common disease through the consecutive year. A systematic control model is developed to recover from the common diseases associated with hospital admitted child patients' management.

Conclusion: If the medical authority can take advances in preventive measures through health awareness, quality training, safe health care with equipment, facilities and trained-up personnel, then the mortality and morbidity can be reduced suggestively in connection with dynamic National Health Policy and Sustainable Development Goals 2030.
\end{abstract}

Keywords: Common Disease; Child Patients; Paediatric Ward; Death Records.

\section{Introduction}

Common childhood diseases are acute respiratory tract infection (ARI), diarrhoea, malnutrition and febrile convulsions, which causing maximum death of children. Most of the death occurred in under-developed and developing countries like Bangladesh. The common causes of neonatal and under-five mortalities are mainly due to perinatal asphyxia, preterm low birth weight, sepsis, congenital abnormalities, ARI, diarrhoea, malnutrition, malaria, measles, drowning etc. in Bangladesh. Out of them, neo-natal deaths are about two-thirds of all infant deaths in Bangladesh (Ullah et al., 2019); Mollah and Nahar, 2018,). In ARI, pneumonia is most common, which is an acute inflammation in lung parenchyma (Khan \& Rahman, 2011), the leading infectious causes of death among children of under-five years' old (Khan \& Rahman, 2011; ICDDRB, 2015). Nearly 6.3 billion children below 5 years die in each year in the world (Mollah and Nahar, 2018). Diarrhea and ARI and were main causes of child mortality, accounting for 8.9 and \%, 15.5 respectively, of deaths among children under 5 years of age in 2015 (Liu et al., 2016). Almost the 16\% of deaths of children under this age occurred in ARI. Tremendous improvement in child survival has been made over the past 20 years (UN IGME, 2019). In Bangladesh, between 1990 and 2011 , under -5 mortality decreased from 151 to 53 per 1000 live births (LBs). The infant mortality rate fell less rapidly from 87/1000 to 43/1000 LBs over the last 18 years. Mortality declines are associated with improved coverage of effective interventions to prevent or treat the most important causes of child mortality and with improvements in socioeconomic conditions.

ARI can be caused by a wide range of bacteria, viruses and also seldom fungal and parasite infections. In Bangladesh, co-morbidity of ARI and malnutrition is prevalent and frequently associated with death. This disease accounts for approximately $15 \%$ of $1,19,000$ deaths among Bangladeshi children aged less than five years (Chowdhury et al., 2020). About $36 \%$ of children aged less than five years are malnourished and $12 \%$ of them have severe acute malnutrition in Bangladesh. The Two-thirds of the malnourished children admitted to hospital are diagnosed with ARI, which is crucial to target malnourished children with ARI with the highest risk of death to have a significant impact on global child mortality through proper ARI case management. The most common causes of diarrhoea include mostly viruses, also bacteria (Chowdhury et al., 2020). Febrile convulsion commonly occurs in between the age of 6 months and 60 months with a temperature of $38^{\circ} \mathrm{C}$ or higher, those are not due to central nervous system (CNS) infection or any metabolic imbalance and occur in the absence of a history of previous afebrile seizure (Mollah and Nahar, 2018). Careful monitoring of patients and on call service should also be in place (Maswood, 2019). Those diseases may present with so many complications (Sethi, 2019). 
The study considered the collected quantity data for rate of occurrence, status and death of child patients (Lozano et al., 2012). The aim of this study is to evaluate the common childhood diseases admitted in hospital.

\section{Research methods}

This study was conducted at the department of Paediatrics in Northeast Medical College Hospital (NEMCH), Sylhet, Bangladesh (Figurer 1) from January 2017 to December 2019. Primary and Secondary data were collected as following manners.

\subsection{Questionnaire survey}

Questionnaire surveys with primary data were collected from the NEMCH, Sylhet in Bangladesh pertaining on common diseases in children from the existing ward. Child patients' data were collected through simple and structured questionnaire survey among 100 respondents (patients) from this department (Table 1) including patients' variation, sex, family class, occupation, same history in family and family member with their health status. Informal discussion is integrated with the patient's guardian like father, mother, grandmother, aunt, uncle etc. at Northeast Medical College Hospital. Meanwhile secondary data were collected from diverse sources like ICDDRB, NEMCH central library, journals, daily news, books, different web pages and relevant update sources.

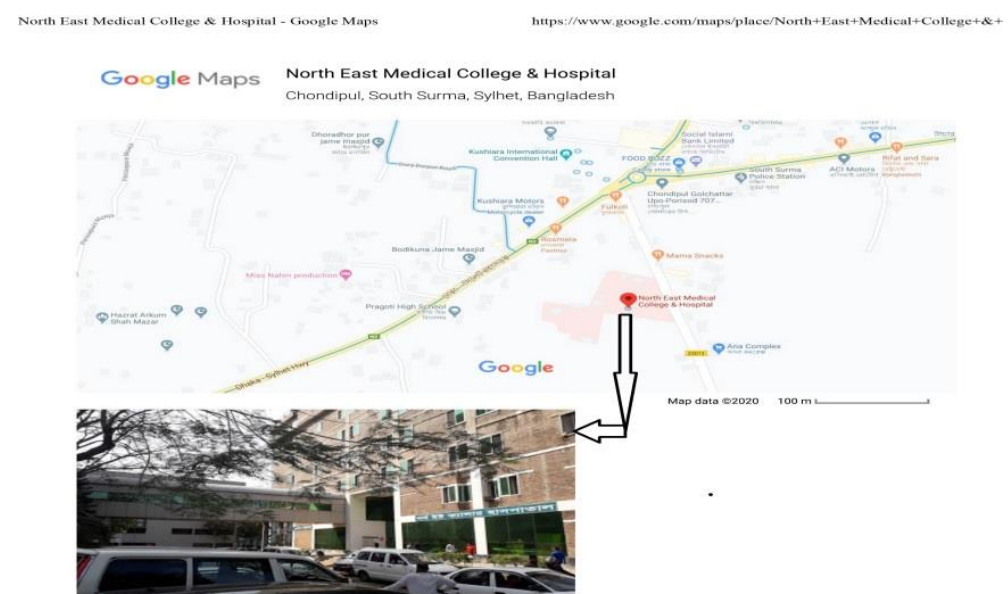

Fig. 1: Map of Northeast Medical College \& Hospital, Sylhet, Bangladesh (Google Map, 2020).

Table 1: Child Patient's Profiling Data

\begin{tabular}{|c|c|c|c|}
\hline Eliments & Social-well-being indicators & Rate of Occurrence & $\%$ \\
\hline \multirow{2}{*}{ Patients variation } & Neonate & 10 & $10 \%$ \\
\hline & General & 90 & $90 \%$ \\
\hline \multirow{3}{*}{ Sex } & Male & 50 & $50 \%$ \\
\hline & Female & 50 & $50 \%$ \\
\hline & Rich & 20 & $20 \%$ \\
\hline \multirow[t]{3}{*}{ Family class } & Middle & 60 & $60 \%$ \\
\hline & Poor & 20 & $20 \%$ \\
\hline & Housewife & 80 & $80 \%$ \\
\hline \multirow[t]{2}{*}{ Occupation } & Business & 10 & $10 \%$ \\
\hline & Job & 10 & $10 \%$ \\
\hline \multirow{3}{*}{ Family history of same disease } & Yes & 50 & $50 \%$ \\
\hline & No & 50 & $50 \%$ \\
\hline & 3 members & 20 & $20 \%$ \\
\hline \multirow[t]{2}{*}{ Number of Family Member } & 4 members & 40 & $40 \%$ \\
\hline & More members & 40 & $40 \%$ \\
\hline
\end{tabular}

\subsection{Selection criteria}

Common diseases are ARI, Diarrhoea, Malnutrition, Febrile convulsion and also death records within the mentioned period from the department of Paediatrics, NEMCH.

\subsection{Data compilation}

All primary, secondary and general information regarding common diseases and death reports, patients' data were compiled according to research objective.

\subsection{Data analysis and interpretation}

Compiled data were integrated for analysis and interpretation as findings using standard data analysis software like SPSS version 26, MS Excel 2016 and R programming version 3.5. 


\section{Results}

From patients' data were illustrated on their age differences, sex variations, family status, occupational background with common disease ideas at NEMCH, which as shown in Figure 2. The finding represents on neonate and general patient, where maximum $60 \%$ of middle classes.
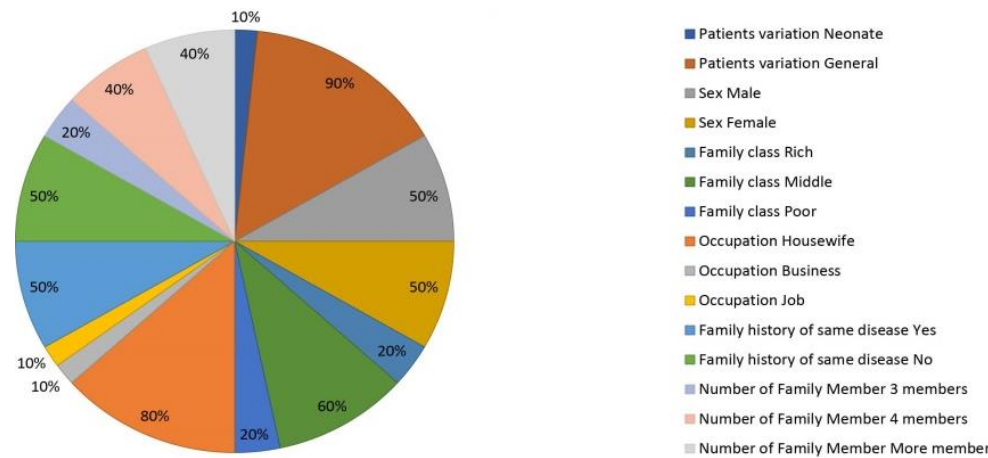

Fig. 2: Child Patient's Profiling at Paediatric Department of NEMCH.

Health awareness in common diseases, particularly idea of ARI, diarrhoea, and malnutrition associated with sanitation, drinking water, service satisfaction and patient's status, which as shown in Figure 3. The study denotes the idea of diarrhoea is maximum and minimum in malnutrition among child patients.
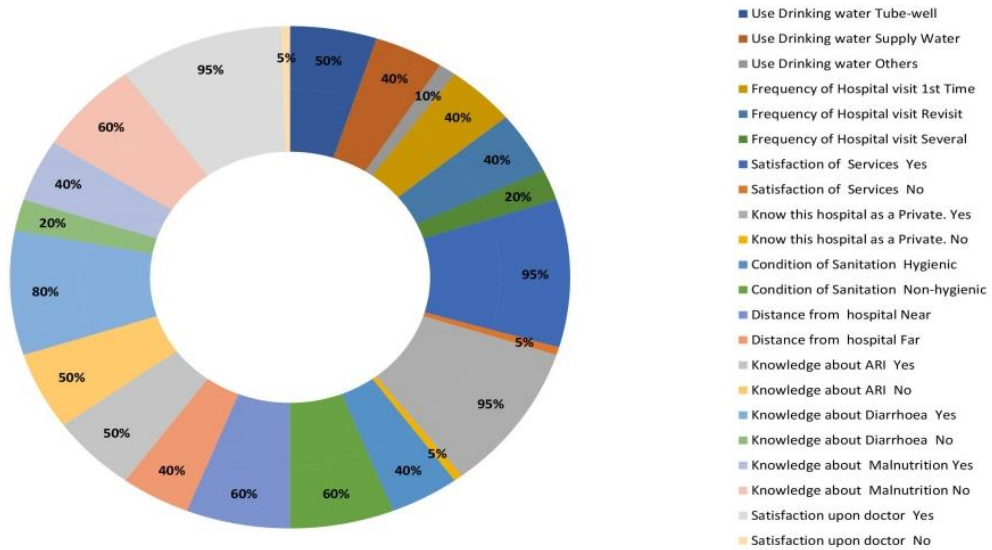

Fig. 3: Health Status of Children and Disease Ideas of Guardians.

\subsection{Patients' summary}

From field records, the grand total of patients at Paediatric department is 10737, out of them 3594 in 2017, 3329 in 2018 and 3814 in 2019. But in the year 2019, the patients were maximum, which as shown in Figure 4. The curve also indicated with linear equation for child patients to compare with different years.

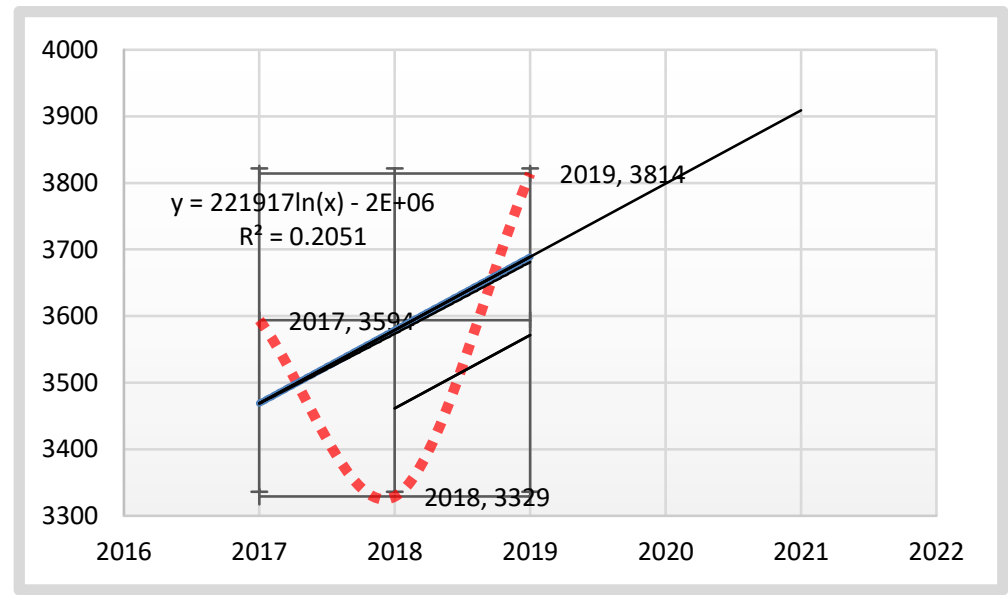

Fig. 4: Child Patients' Status at Paediatric Department of NEMCH.

\subsection{Age gradation patient's status}

From survey, at NEMCH, there are 3622 neonatal and 7115 general patients (other than neonate) at Department of Paediatrics from January 2017 to December 2019, among them, the general patients are more than neonatal disease, which as shown in Figure 5. The figure also showed with polynomial graph to compare with different years in general patients. 


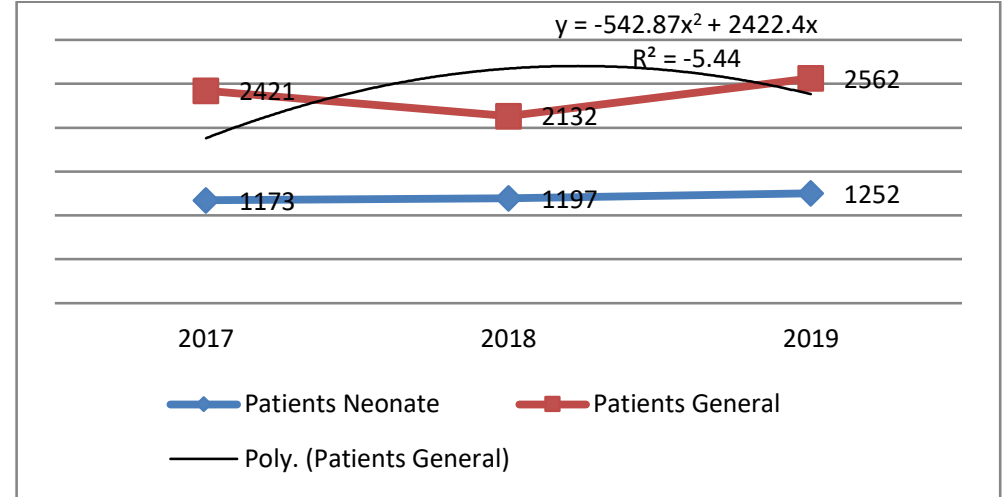

Fig. 5: Different types of Patients Status at Paediatric Department of NEMCH.

\subsection{Sex distribution}

From patient register, the total number of neonate are male 1915 and female 1707, meanwhile general male 3628 and female 3487 of patients at Department of Paediatrics from 2017 to 2019. Round the year the disease prevalence, neonate and general male are more predominant than female, which as shown in Figure 6. The curve also indicated with logarithm line for patients to compare with different sex variations.

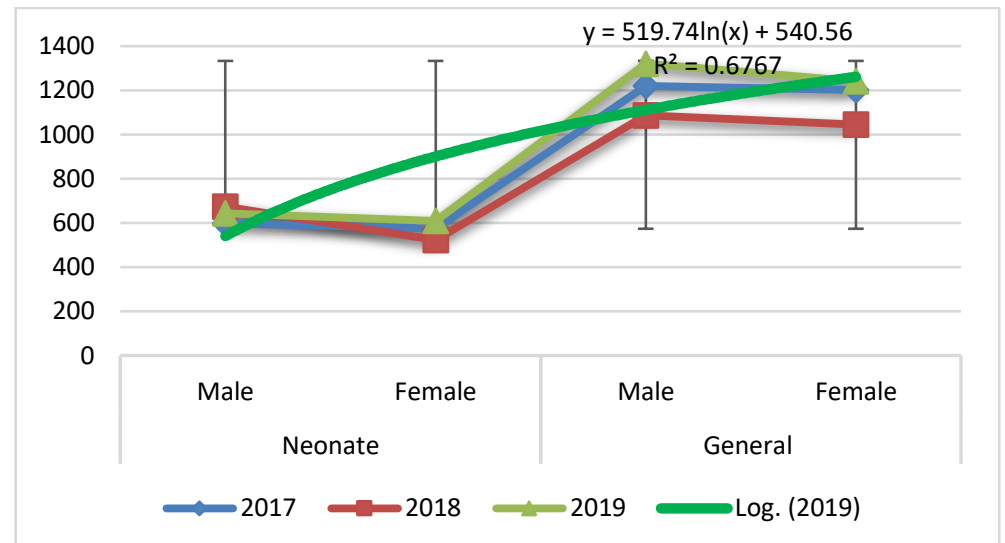

Fig. 6: Sex Variations in Different Patient Status at Department of Paediatrics of NEMCH.

\subsection{Year wise disease prevalence}

From the year wise distribution of common diseases at $\mathrm{NEMCH}$, in 2017 and 2018, the predominance of diarrhoea were more in 856 and 562 respectively. On the other hand, in 2019, ARI was maximum in 730 in number than other diseases, which as shown in Figure 7.

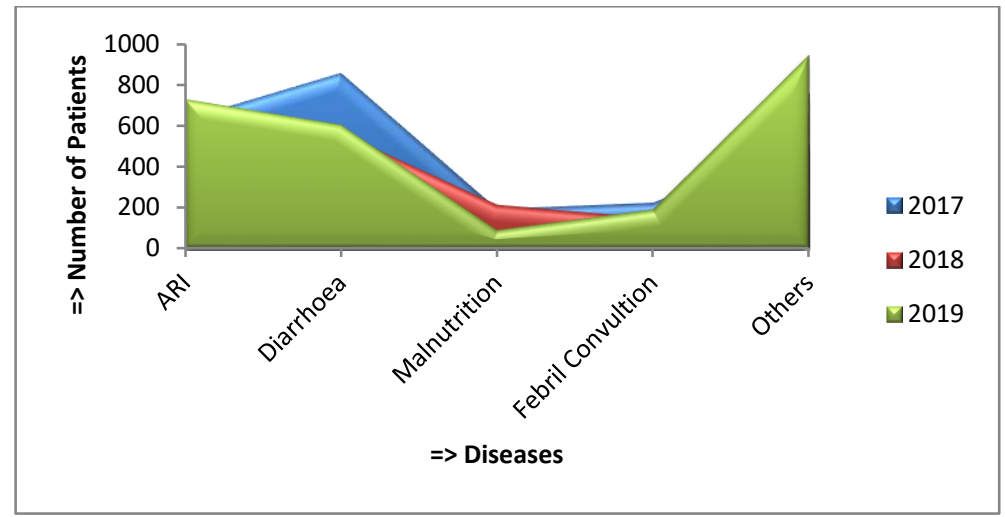

Fig. 7: Year Wise Distribution of Various Patient Status at Department of Paediatrics, NEMCH.

\subsection{Monthly distribution of common diseases}

From the assessment at NEMCH, the total patients are 4977 including ARI, diarrhoea, malnutrition and febrile convulsion from January 2017 to December 2019. These mentioned diseases are epidemic diseases except malnutrition. The study observed that ARI is maximum in the end of the year, diarrhoea is maximum in the end and beginning of the successive years, febrile convulsion is more in the middle of the year and also malnutrition is more in round the year which as shown in Figure 8. The study opined for preventive measure before the stipulated periods. 


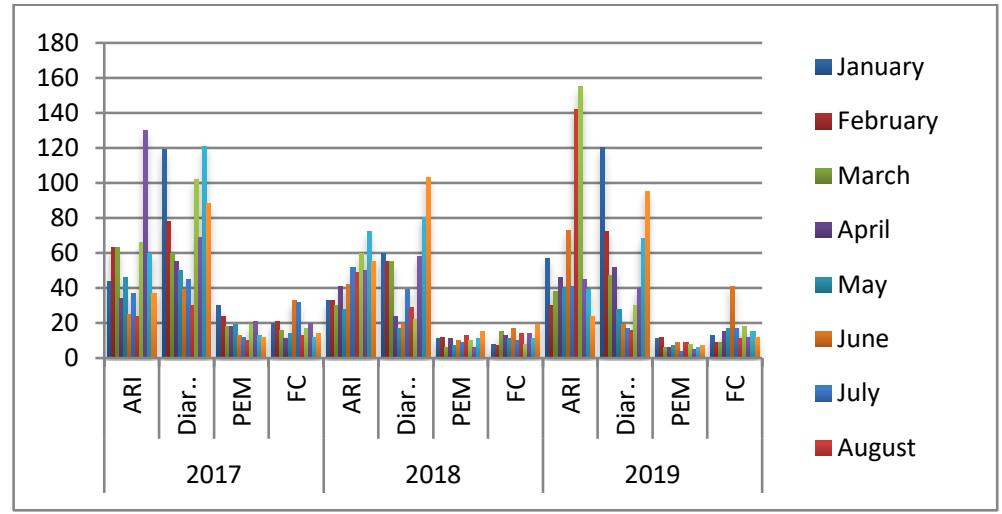

Fig. 8: Month wise Distribution of Common Diseases in Different Years.

\subsection{Death report of child patients}

From death records at NEMCH, there are 101 neonatal and 84 general patients' deaths at Department of Paediatrics from January 2017 to December 2019, among them, the neonatal deaths are more than general death, which as shown in Figure 9. The figure also proved with linear line to compare with different years in general patients and neonate.

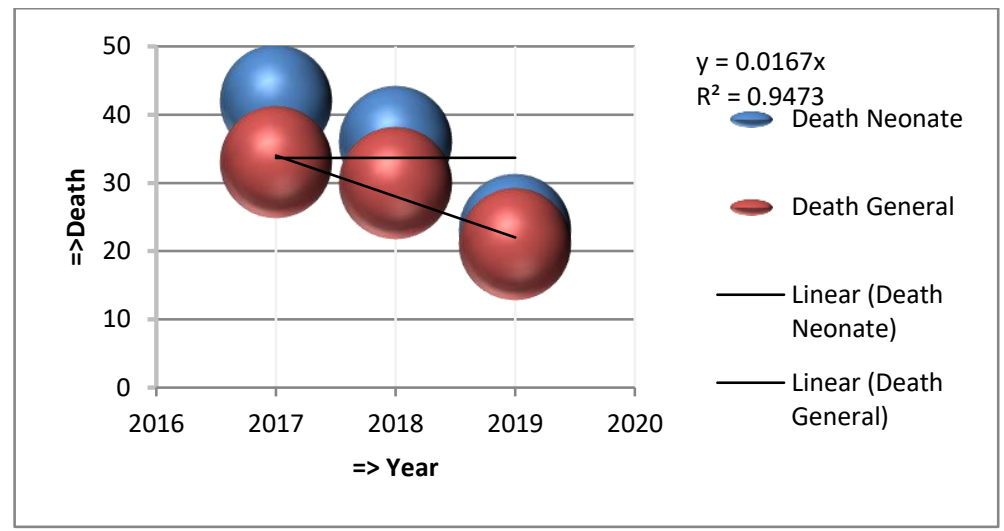

Fig. 9: Year Wise Death Prevalence at Department of Paediatrics, NEMCH.

\section{Discussion}

The study has represented that child patients both neonate and general associated with common diseases admitted at the Department of Paediatrics in Northeast Medical College Hospital from 2017 to 2019. The findings are exposed to different common diseases including ARI, Diarrhoea, Malnutrition, Febrile convulsion and others. However, the incidence of ARI is more in September, October and November, but Diarrhoea is more in November, December and January in each year. And also, febrile convulsion is more in June; malnutrition is more in round the year. In 2017 the common diseased patients are more but in 2019, it is declined. It has mentioned that the death record is gradually reducing in the successive year. If the high authority can take earlier preventive measure then the mortality and morbidity can be reduced significantly (Dock et al., 2017). ARI may infect via touching, sneezing, coughing and also even breathing. The common age of incidence is in between 2 months to 2 years. Fast breathing, cough-cold and fever is usual common symptoms in this disease. The hospital authorities can arrange proper diagnosis and management of all patients and suspected cases accordingly. Out of hospital admitted patients, the most common case is ARI and Diarrhoea (Hoang et al., 2019). Most of them treated accordingly to take weeks to recover completely. These difficult conditions are too much significant due to great mortality and illness. In addition, sometimes it may remain asymptomatic or silent (Son et al., 2017).

Life-threatening problems can happen if the patient is severely immune compromised or has gone for long time without treatment. It is possible to death of children due to ARI and Diarrhoea so doctors will propose the condition earlier (Johnson, 2018; Green et al., 2019). The research mentioned that mortality can be reduced with the proper coverage, management and prevention of severe causes of child mortality according to progress in social status (MOHFW, 2015). In Bangladesh, child mortality rate reduces within successive year, for example in 2010 the value was 49.1 but the value reduces 30.2 in 2018 (WDA, 2020). If we can give proper awareness about vaccination, and maintain hygiene, hand washing, safe drinking water, purer sanitation, exclusively breast feeding and weaning, healthy life style, living in quiet and calm environment, we can more prevent these diseases as well as decreases morbidity and mortality. The authority of hospital has arranged a super model of sustainable health service delivery for various low-middle-income groups, delivering a full spectrum of in-patient, emergency, surgical, diagnostic, lab and pathology, out-patient, and other expert care under one roof and through medical professionals, trained-up nurses/paramedics and technologists. Now a day's microbiologist revealed that the lung is not germfree, and quarantines in case of different diseases with aerobes and diverse culture [Neil and Dean, 2019].

For treatment purpose, ARI need broad spectrum coverage of antibiotic are necessary to improve the condition and manage quickly to prevent further complications. Moreover, the aiming of prevention enhanced relevant diseases and reducing mortality and morbidity are realistic. Serious problems can happen if the patient is severely compromised immune or has gone for long time without treatment. The study mentioned that mortality can be reduced with the effective coverage, treatment and prevention of severe causes of child mortality according to progress in social status (MOHFW, 2015). A dietitian should give emphasis for adequate feeding and maintenance of proper nutrition of the child. Administration of humidified oxygen and nebulization with bronchodilator can be given. We can reduce this by identifying the risk factors and colonization of pathogenic organisms. A comprehensive neonatal emergency service had been organized 
in place for improvement (Sharif, 2019). There are so many programmes like expanded immunization programme, the Diarrhoeal disease control programme, deworming, Vitamin A supplementation programme, awareness programme regarding clean and save delivery and other nutritional programme played a role in improving child health (Moral, 2019). In Bangladesh, infant mortality rate (IMR) is gradually declining (Figure 10). In 2000, the IMR was 64.37 meanwhile now it is approximately 24.73 in 2020 per thousand live births (Statista, 2020).

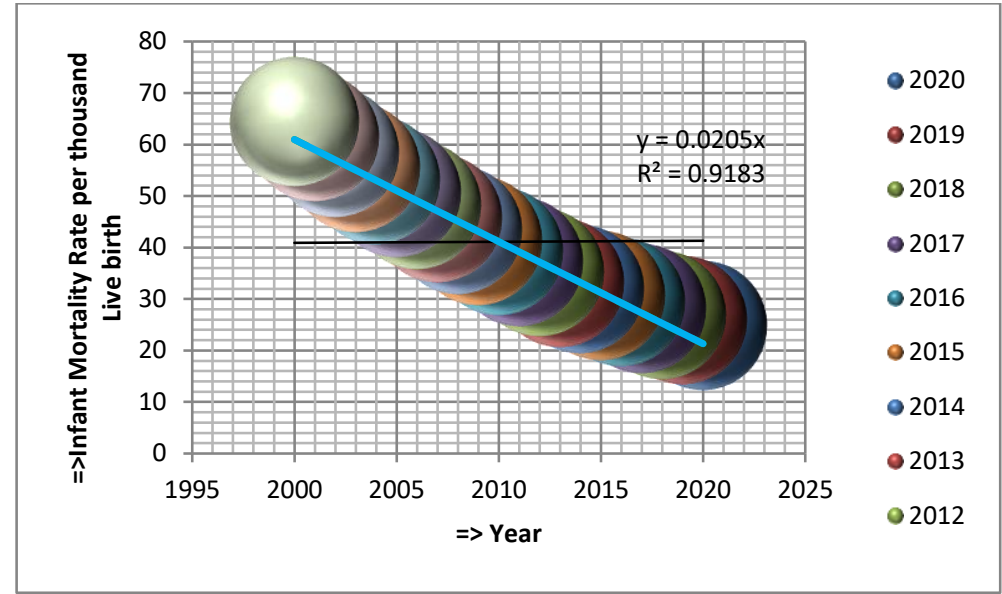

Fig. 10: Infant Mortality Rate in Bangladesh from 2008 to 2018 (Statista, 2020).

Knowledge on common diseases, mind set-up, motivation about risk factors, follow on doctor's advices and nutritional supports can prevent recurrence of these diseases.

\subsection{Systematic control model}

The Systematic Control Model is operative on the priority of condition or situation in connection with management of admitted patients with common diseases. From Figure 11, the research has shown that following parameters enhance with indoor, such as technopsychological supports with awareness, maintenance with nutritional support, associated with vigorous treatment and follow up counseling. Over all, an innovative model with indoor hospital patients is suitable for milestone-setting in case of children for sustainable health service delivery.

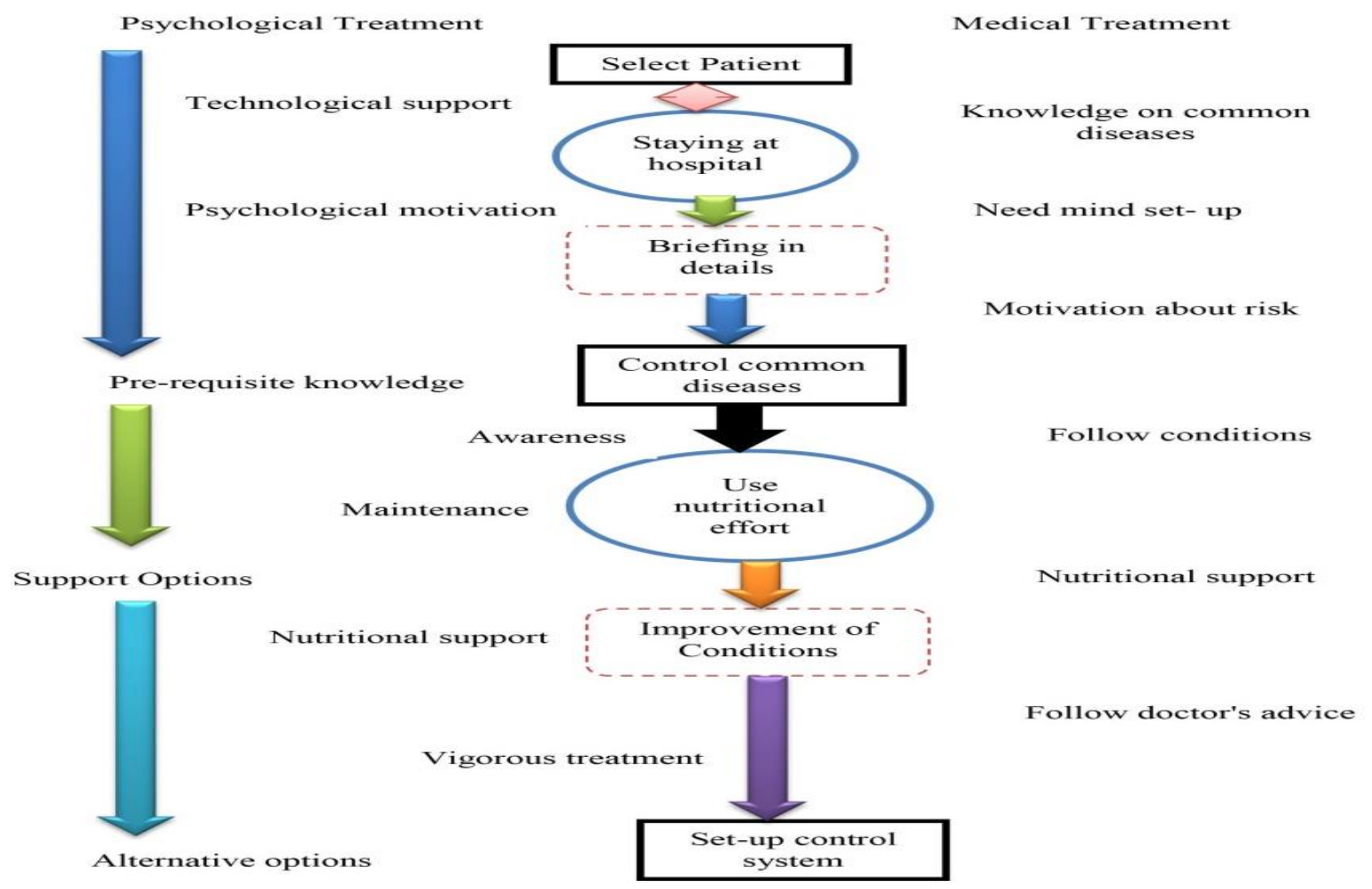

Counseling \& follow up

Prevent recurrence

Fig. 11: Systematic Control Model for Recovery of Common Diseases.

\subsection{Challenges}

There are diverse challenges in research on common diseases admitted in Paediatric ward. However, the guardians have lack of knowledge about diseases and their prevention. Corona disease is also pandemic in connection with common diseases. There are limited data on common diseases research and less technological support. The Sustainable Development Goals adopted by the United Nations in 
2015 were developed to promote healthy lives and well-being for all children to reduce under-five mortality to at least as low as 25 per 1,000 live births in every country (WHO, 2019). Bangladesh, as a developing country, it is difficult to fulfill the targets of SDGs due to unwanted situation.

\section{Conclusion}

Common disease patients at Paediatric department augment the study in connection with neonate and general types in both male and female sexes with 1: 0.93 . The prevalence of ARI is more in the end of the year but diarrhoea in the end and beginning of the following year, febrile convulsion in the middle part of the year, and malnutrition is round the year. Moreover, the death record is gradually reducing in the successive year. If the higher authority can take earlier precautionary measure to provide high quality service, safe health care and training with appropriate policies, equipment, facilities and personnel then the mortality and morbidity can be reduced significantly linking with National Health Policy and Sustainable Development Goals 2030. The study recommends for future research trajectory with methodological agenda on common disease recovery approach in private medical college hospitals.

\section{Disclosure}

Data Availability

The data are being used to support the findings of this research work are available from the corresponding author upon request.

\section{Competing Interests}

The authors declare no potential conflict of interests in this research work.

\section{Acknowledgements}

The authors acknowledged the authority of $\mathrm{NEMCH}$, Sylhet, Bangladesh for kind support.

\section{Authors Contributions}

MSK designed the study. MRM wrote the first draft of the manuscript with TH, BU, SMQ and YT reviewing and amending the initial draft. All authors read and approved the final version of the manuscript.

\section{References}

[1] Chowdhury, F., Shahid, ASMSB, Ghosh, PK., Rahman, M., Hassan, MZ. Akhtar, Z., Muneer, SM., Shahrin, L., Ahmed, T. and Chisti, MJ. (2020). Viral etiology of ARI among severely malnourished under-five children in an urban hospital, Bangladesh. PLoS One, 15 (2), e0228329. https://doi.org/10.1371/journal.pone.0228329.

[2] Dock, E., Boskey, E., Watson, K. and Wu, B. (2017). Aspiration ARI: Symptoms, Causes, and Treatment. Healthline, 1-7. url: https://www.healthline.com/health/aspiration-ARI (Accessed time on March 1, 2020 at $10 \mathrm{am}$ ).

[3] Green, A., Bramley, P., Thomas, M, Brown, J. and Manara, A. (2019). Percutaneous Tracheostomy Practice in a U.K. Major Trauma Centre: A Report on 519 Procedures. Journal of the Intensive Care Society, 20(2), Supplement 1-253. https://doi.org/10.1177/1751143719835452.

[4] Google Map (2020). Map of Northeast Medical College and Hospital, Chondipul, South Surma, Sylhet, Bangladesh. URL: https://www.google.com/maps/place/North+East+Medical+College+\%26+Hospital/@

[5] 24.8645429,91.854723,17z/data=!3m1!4b1!4m5!3m4!1s0x3751aae9663019c7:0x4bf6e960672dc2c0!8m2!3d24.8645429!4d91.8569117.

[6] Hoang, V.T., Dao, T.L., Minodier, P., Nguyen, D.C., Hoang, N.T., Dang V.N. and Gautret, P. (2019). Risk Factors for Severe ARI According to WHO 2005 Criteria Definition Among Children <5 Years of Age in Thai Binh, Vietnam: A Case-Control Study. Journal of Epidemiology and Global Health, 9(4), 274-280. https://doi.org/10.2991/jegh.k.191009.001.

[7] ICDDRB. (2015). ARI and other respiratory diseases. A brief guide to ARI and other respiratory diseases, and their impact globally and in Bangladesh. url: https://www.icddrb.org/news-and-events /press-corner/media-resources/ARI-and-other-respiratory-diseases (Accessed time, March 8, 2020 at $01: 00 \mathrm{pm}$.

[8] Johnson, J. (2018). Everything you need to know about aspiration ARI. Medical News Today, 1-5. url: https://www.medicalnewstoday.com/articles/322091

[9] Khan, M.R. and Rahman, M.E. (2011). Respiratory Diseases: ARI (chap.7). Essence of Pediatrics. [4th ed.]. Elsevier Publisher, New Delhi, India, ISBN978-81-312-2804-3, 118-123.

[10] Liu, L., Oza, S., Hogan, D., Chu, Y., Perin, J., Zhu, J. et al. (2016). Global, regional and national causes of under-5 mortality in 2000-2015: an updated systematic analysis with implications for the Sustainable Development Goals. The Lancet, 388 (10063), $3027-3035$. https://doi.org/10.1016/S0140-6736(16)31593-8.

[11] Lozano, R., Naghavi, M., Foreman, K., Lim, S. and Shibuya, K. et al. (2012). Global and regional mortality from 235 causes of death for 20 age groups in 1990 and 2010: a systematic analysis for the Global Burden of Disease Study 2010. Lancet, 380, 9859, $2095-128$. https://doi.org/10.1016/S0140-6736(12)61728-0.

[12] Maswood, M.H. (2019). Childhood ARI. ICDDRB (Integrated Cholera and Diarrhoeal Disease Rehabilitation, Dhaka, Bangladesh. url: www.newagebd.net/credit/manzur h maswood (Accessed time February 11, 2020, time 1:00 pm.)

[13] MOHFW (Ministry of Health and Family Welfare). (2015). Bangladesh, Partnership for Maternal, Newborn \& Child Health, WHO, World Bank and Alliance for Health Policy and Systems Research. Success Factors for Women's and Children's Health: Bangladesh. 1-2.

[14] Mollah, M.A.H., and Nahar, N.(2018). ARI. Step on to Paediatrics, (4 ${ }^{\text {th }}$ edi), Ogro Printing and Packaging Industry, Dhaka, Bangladesh. 87-88, ISBN-978-984-33-0987-7.

[15] Moral, S. (2019). Infant mortality rate not decreasing. The Prothom Alo, December 3, 2019, url: https://en.prothomalo.com/bangladesh/Infantmortality-rate-not-decreasing.

[16] Neil, S. and Dean, N. (2019). Aspiration ARI and pneumonitis: a spectrum of infectious / noninfectious diseases affecting the lung. Current Opinion in Infectious Diseases, 32(2), 152-157. https://doi.org/10.1097/QCO.0000000000000524. 
[17] Sethi, S. (2019). Aspiration Pneumonitis and ARI. University at Buffalo, the State University of Newyork. 1-3. url: ttps://www.merckmanuals.com/professional/pulmonarydisorders/ARI/aspiration-pneumonitis-and-ARI (Accessed time on March 1, 2020 at 8.00 am)

[18] Sharif, M. (2019). Infant mortality rate not decreasing. The Prothom Alo, December 3, 2019, url: https://en.prothomalo.com/bangladesh/Infantmortality-rate-not-decreasing.

[19] Son, Y.G., Shin, J. and Ryu, H.G. (2017). Pneumonitis and ARI after aspiration. Journal of Dental Anesthesia and Pain Medicine, 17(1): 1-12. https://doi.org/10.17245/jdapm.2017.17.1.1.

[20] Statista (2020). Bangladesh: Infant mortality rate from 2008 to 2018. url: https://www.statista.com/statistics/806665/infant-mortality-inbangladesh/ (Accessed time to May31, 2020 at 02:00 pm national time).

[21] Ullah, M.B., Mridha, M.K., Arnold, C.D., Matias,S. L., Khan, M.S.A., Siddiqui, Z., Hossain, M., Paul, R.R., and Dewey, K.G. (2019). Factors associated with diarrhea and acute respiratory infection in children less than two years of age in rural Bangladesh. . BMC Pediatrics, 19:386, 1-11. doi https://doi.org/10.1186/s12887-019-1738-6.

[22] UN IGME. (2019). Levels \& Trends in Child Mortality. Estimates developed by the UN Inter-agency Group for Child Mortality Estimation (UN IGME). Report 2019. 1-52. url: http://s30184.p584.sites.pressdns.com/resources/levels-and-trends-in-child-mortality/

[23] WDA (World Data Atlas). (2020). what is Bangladesh Child Mortality Rate? Bangladesh Health. URL: https://knoema.com/atlas/Bangladesh/Child-mortality-rate (Accessed time March 5, 2020 at 10: $00 \mathrm{am}$ ).

[24] WHO (World Health Organization) (2019). Key Facts for Children: reducing mortality. url: https://www.who.int/news-room/factsheets/detail/children-reducing-mortality. 